\title{
Penicillinase-producing Neisseria gonorrhoeae isolated in Surabaya
}

\author{
AGUS SOENDJOJO,* ATASIJATI IDAJADI,† YUSUF BARAKBAH,* AND \\ MOCHAMAD I ILIAS* \\ From the Departments of *Dermatovenereology and †Microbiology, Airlangga University, Surabaya, \\ Indonesia
}

SUMMARY Although penicillinase-producing strains of Neisseria gonorrhoeae (PPNG) were v discovered in 1976 in neighbouring countries, not until 1980 were such strains isolated and identified in Indonesia. In that year PPNG were detected in three male patients with gonococcal urethritis in Surabaya. The minimum inhibitory concentration of penicillin $\mathbf{G}$ for all three strains was $12 \cdot 5 \mu \mathrm{g} / \mathrm{ml}$.

\section{Introduction}

In $1976 \beta$-lactamase or penicillinase-producing Neisseria gonorrhoeae (PPNG) were first discovered in England and in the USA. ${ }^{2}$ At the end of that year PPNG were identified in Singapore, the Philippines, Australia, and Japan, and epidemiological information indicated their presence also in Thailand and Hongkong. ${ }^{3}$ Alarmed by these reports, we have been on the alert over the past few years to the existence of such strains in Indonesia. But despite the rapidly increasing traffic between those countries and Indonesia, it was not until 1980 that PPNG were recognised during a survey for gonorrhoea among prostitutes in Jakarta (Wijaya, unpublished data). Recently, we isolated and identified PPNG from three male patients with uncomplicated gonococcal urethritis in Surabaya during a clinical trial with rosoxacin-a new quinolone derivative ${ }^{4}-$ in the treatment of gonorrhoea.

\section{Patients and methods}

Seventy-three male patients with signs and symptoms of urethritis attending the department of dermatovenereology between June and July 1980 were examined for $\boldsymbol{N}$ gonorrhoeae.

\section{ISOLATION AND IDENTIFICATION}

Specimens from the urethra, collected with sterile cotton swabs, were inoculated directly on to

Address for reprints: $\operatorname{Dr}$ A Soendjojo, Department of Dermatovenereology, Medical Faculty, Airlangga University, Jl Dharmahusada 47, Surabaya, Indonesia

Accepted for publication 24 June 1981 modified Thayer-Martin medium and incubated in a candle jar at $37^{\circ} \mathrm{C}$ for 48 hours. $N$ gonorrhoeae was identified by colonial morphology, microscopical examination of Gram-stained smears, oxidase reaction, and fermentation tests.

\section{SENSITIVITY TO PENICILLIN}

Strains of gonococci isolated in culture were tested for sensitivity to penicillin $G$ by the disc diffusion method. To recognise penicillinase formation, 10-IU penicillin discs were used; if the diameter of the zone of inhibition was smaller than $20 \mathrm{~mm}$ a starch iodine test for $\beta$-lactamase production was carried out. ${ }^{3}$ The minimum inhibitory concentrations (MICs) of penicillin $\mathrm{G}$ were determined in only the three strains of gonococci producing penicillinase. A plate dilution method using chocolate agar containing penicillin $\mathrm{G}$ in dilutions from $0.05 \mu \mathrm{g} / \mathrm{ml}$ to $50 \mu \mathrm{g} / \mathrm{ml}$ was used.

\section{Results}

Sixty strains of gonococci were isolated from the 73 을. patients studied. Using 10-IU penicillin G discs, 40 N isolates had a decreased sensitivity to the antibiotic tested. On further investigation by the iodometric $N$ method, three of the penicillin-insensitive strains $\omega$ produced $\beta$-lactamase. The MIC of penicillin $G$ for 2 all the three penicillinase-producing strains was 12.5 을 $\mu \mathrm{g} / \mathrm{ml}$. The infections were apparently acquired from prostitutes, and the three patients harbouring these $\stackrel{+}{+}$ strains were all cured with rosoxacin $300 \mathrm{mg}$ in a 0 single oral dose. Attempts to trace the patients' contacts and determine whether these also harboured PPNG were unsuccessful. 


\section{Discussion}

Although PPNG had been discovered in 1976 in neighbouring countries, ${ }^{3}$ it was not until 1980 that such strains were isolated and identified in Indonesia, despite mass tourism and increasing traffic between those countries and Indonesia over the past few years. This is more surprising if we consider that the penicillinase gene is plasmid-borne. If it is assumed that the plasmid is transferred from other bacteria in an area where penicillin and ampicillin are used intensively, one would expect that the indiscriminate use of these antibiotics would create an environment favouring such genetic change. In this country, however, in-vitro studies are carried out only sporadically during surveys and clinical studies, and the number of isolates obtained may not represent the gonococcal population in the whole area. Moreover, there is a great tendency for practitioners to change from penicillin to penicillinase-resistant antibiotics as soon as treatment failure occurs without performing sensitivity tests.

The discovery of PPNG creates a new problem in combating gonorrhoea, as in our country penicillin and its derivatives are still recommended for its routine treatment. It is therefore important to screen the community, especially the high-risk groups, to determine the extent of the reservoir of gonococcal infection, to ascertain the sensitivity pattern of the local strains to the commonly available antigonococcal agents, and to detect the presence of PPNG. Financial limitations and inadequate laboratory facilities in most developing countries, however, make it difficult to put these essential measures into practice.

\section{References}

1. Phillips I. $\beta$-lactamase-producing penicillin-resistant gonococcus. Lancet 1976; ii: 656.

2. Ashford WA, Golash GR, Henning VG. Penicillinaseproducing Neisseria gonorrhoeae. Lancet 1976; ii: 657.

3. World Health Organisation. Neisseria gonorrhoeae and gonococcal infections. Technical Report Series, No 616. Geneva: WHO, 1978.

4. O'Conner J, Dorson RA, Came PE, Wagner RB. Rosoxacin, a new synthetic agent for the treatment of systemic Gramnegative infections. In: Proceedings of the 11th ICC and 19th ICAAC American Society of Microbiology 1980;1:440-2. 